\title{
IDENTIFICAÇÃO E ANÁLISE DE MORFODINÂMICAS DO RELEVO DA ÁREA DE INFLUÊNCIA DO ESCUDO SUL-RIO-GRANDENSE NO MUNICÍPIO DE PELOTAS, RS
}

\author{
Danilo da Silva Dutra ${ }^{(a)}$ Moisés Ortemar Rehbein ${ }^{(\mathrm{b})}$
}

(a) Universidade Federal de Pelotas-UFPEL, danilodasilvadutra@ hotmail.com

(b) Departamento de Geografia da Universidade Federal de Pelotas-UFPEL, moisesgeoufpel@gmail.com

\section{EIXO: SISTEMAS GEOMORFOLÓGICOS: ESTRUTURA, DINÂMICAS E PROCESSOS}

\section{Resumo}

Este trabalho é parte de um projeto maior, o qual intitulado de mapeamento geomorfológico do município de Pelotas. Este município está localizado no sul do estado do Rio Grande do Sul, sobre morfoesculturas do relevo do estado de morfocronogêneses bastante distintas, a Planície Costeira e o Escudo Sul-Rio-Grandense. Este trabalho tem como objetivo principal o mapeamento de padrões de formas semelhantes de relevo e identificação de morfodinâmicas associadas, na área de influência do Escudo Sul-Rio-Grandense no município de Pelotas/ RS. Enquanto orientações metodológicas, seguem-se pressupostos de Ab'Saber (1969) e Ross (1992). Para a operacionalização da pesquisa, realizaram-se atividades alternadas entre o gabinete (revisões bibliográficas e elaboração de documentos cartográficos) e trabalhos de campo (verificação de dados cartografados em gabinete, análises visuais e táteis de materiais pedogenéticos, identificação e análises de formas de processos geomorfológicos atuais, erosivos e deposicionais). $\mathrm{Na}$ área de estudos, foram mapeados padrões de relevo em morros, morrotes, colinas, planícies (alveolares e fluviais) e cabeceiras de drenagens. As morfodinâmicas do relevo estabelecem pontuais relações com as características geológicas, dos solos, declividades, comprimentos de rampa e geometrias das vertentes, características pluviométricas e dos diferentes tipos de usos e coberturas da terra. Considerando-se essas relações, identificaram-se processos erosivos lineares e, sobretudo, laminares, solapamentos de taludes e assoreamentos fluviais.

Palavras-chave: Geomorfologia de Pelotas/RS; Morfodinâmicas do relevo; Escudo Sul-RioGrandense.

\section{Introdução}

No contexto das aplicações da ciência do relevo se destaca o mapeamento geomorfológico. Este “(...) se constitui num dos principais métodos e produtos da pesquisa geomorfológica" (RODRIGUES, 1997, p. 88). A existência de um plano de informações, representado pelo mapeamento geomorfológico, contribuirá, seguramente, na elucidação de problemas erosivos e deposicionais, assim como viabilizará, mediante combinações com outros mapeamentos temáticos, a elaboração de cenários ambientais, como, por exemplo, áreas de preservação permanente, em conflitos legais de uso ou de riscos de inundações (ARGENTO, 1995).

Este trabalho é parte de um projeto maior, o qual intitulado de mapeamento geomorfológico do município de Pelotas. Este município está localizado no sul do estado do Rio Grande do Sul, sobre morfoesculturas 


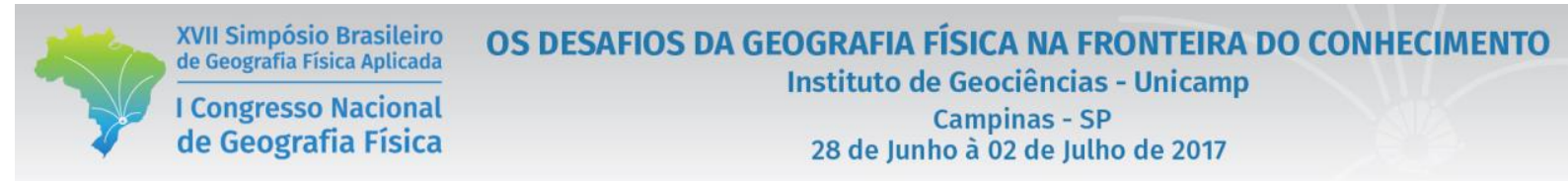

do relevo do estado de morfocronogêneses bastante distintas, a Planície Costeira e o Escudo Sul-RioGrandense. Este trabalho tem como objetivo principal o mapeamento de padrões de formas semelhantes de relevo e identificação de morfodinâmicas associadas, na área de influência do Escudo Sul-RioGrandense no município de Pelotas/RS. Os estudos de morfodinâmicas do relevo atentam ao entendimento dos processos atuais (ativos) sobre o modelado terrestre.

A área de influência do Escudo Sul-Rio-Grandense no município de Pelotas, área de estudos, é de 898,38 $\mathrm{km}^{2}$, correspondendo a aproximadamente $55,8 \%$ da área do município, na porção centro-norte deste (Figura 1).

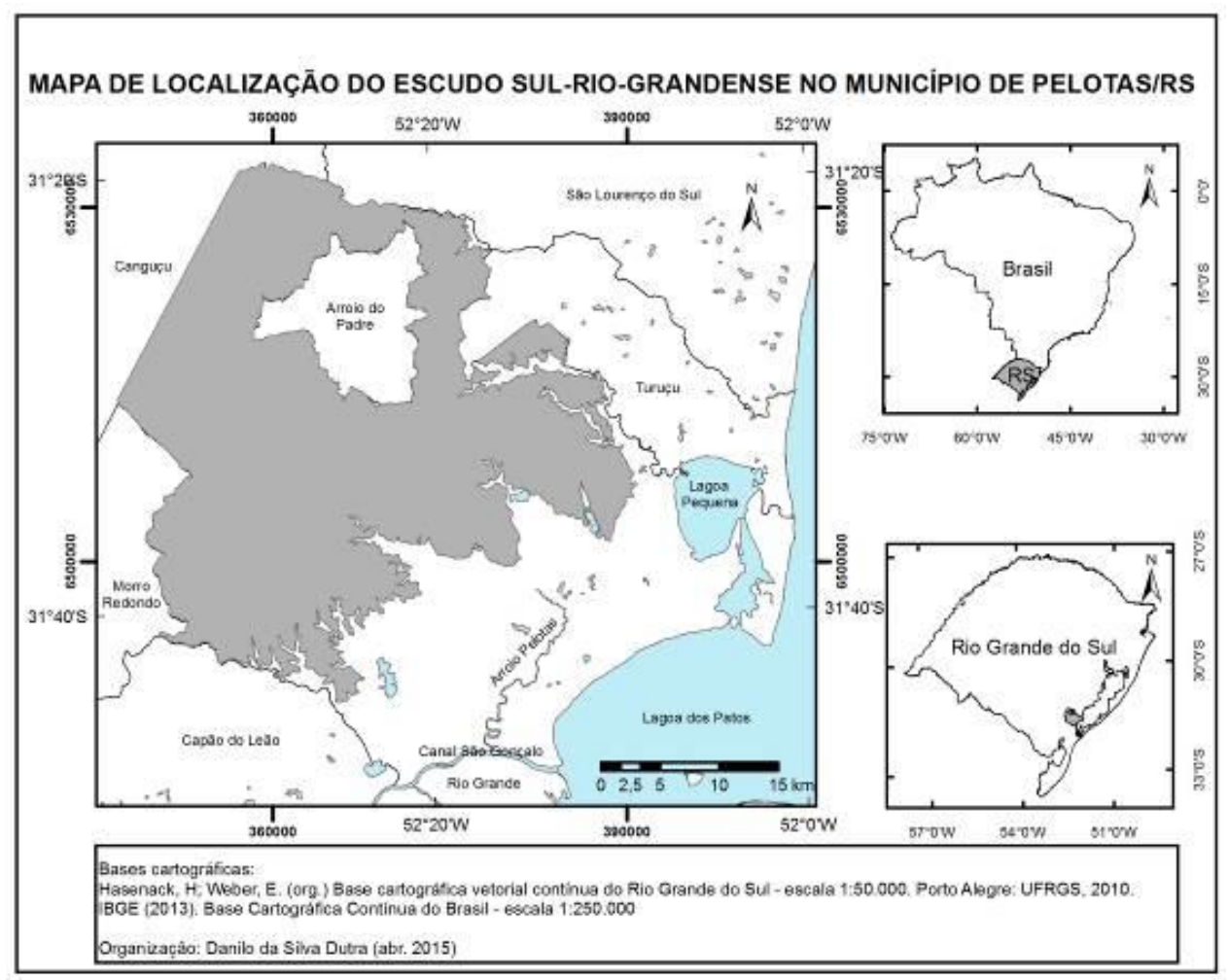

Figura 1: Localização do Escudo Sul-Rio-Grandense no município de Pelotas. Fonte: Próprio autor

$\mathrm{Na}$ área de estudos se desenvolve uma rede hidrográfica de significativa importância ecológica e social para o município de Pelotas e região, da qual cabem destacar seções fluviais dos Arroios Pelotas, Santa Bárbara, Corrientes e Contagem, usados para abastecimento urbano e rural.

O município conta com uma população de 328.275 habitantes (IBGE, 2010). Economicamente, destaca-se em atividades de serviços e agropastoris. Segundo dados sistematizados pela Prefeitura Municipal de Pelotas (2013), a partir de dados do IBGE (2010), o município de Pelotas é o maior produtor de pêssego para indústria de conservas do Brasil e responde por aproximadamente $28 \%$ da produção de arroz, $10 \%$ da 
produção de grãos, $16 \%$ do rebanho bovino de corte, $28 \%$ do rebanho de equinos e detém a maior bacia leiteira (com produção de 30 milhões de litros/ano) do RS. Destaca-se ainda no estado na produção de aspargos, pepinos, figo, fumo, morangos e de lãs.

Como brevemente destacado, o município possui em seu território importantes características físicas e socioeconômicas, um importante sistema hidrológico e variados usos e coberturas da terra, cujas interações resultam em transformações de dinâmicas ambientais. Essas transformações requerem atenção, a fim de mitigações de impactos ambientais.

\section{Pressupostos teóricos e metodologia operacional}

Esse trabalho possui fundamentação teórica e metodológica nos trabalhos de Ab'Saber (1969) e Ross (1992). Ab'Saber (1969) propõe o entendimento do relevo a partir de três níveis taxonômicos, a compartimentação topográfica, a estrutura superficial e a fisiologia da paisagem.

Muito sumariamente, entende-se por compartimentação topográfica a individualização das grandes unidades morfoestruturais: crátons, bacias sedimentares e cinturões orogênicos. A estrutura superficial equivale aos processos erosivos e aos depósitos correlativos (detritos superficiais) provenientes das alterações químicas e físicas das rochas. A fisiologia da paisagem compreende os processos morfoclimáticos e pedogênicos atuais, além da interferência do homem no ambiente (AB'SABER, 1969). Para Ross (1992), o entendimento do relevo pode se dar a partir de seis níveis taxonômicos. Esses níveis taxonômicos se apresentam em ordem genética e cronológica. A primeira taxonomia compreende as unidades morfoestruturais; o segundo nível taxonômico compreende as unidades morfoesculturais; o terceiro nível se define pelos padrões de formas semelhantes do relevo, tais como, padrão em formas tabulares, padrão em colinas, padrão em morros, serras, etc.; o quarto táxon compreende as unidades individualizadas de formas de relevo, como planícies fluviais, terraços fluviais, morros, colinas, etc; o quinto táxon compreende as formas das vertentes de cada uma das formas individualizadas de relevo e o sexto táxon "[...] corresponde às formas menores produzidas pelos processos erosivos atuais ou por depósitos atuais (ROSS 1992, p. 20)". Dentre as formas, pode-se destacar voçorocas, ravinas, bancos de sedimentação atual, formas antrópicas e etc.

Do ponto de vista operacional, esta pesquisa se desenvolveu a partir de revisões bibliográficas, trabalhos de gabinete e saídas de campo. Os levantamentos bibliográficos consistiram na revisão de dados da geologia (CPRM, 2010), pedologia (CUNHA E SILVEIRA, 1996; ROSA (1985), clima e hidrografia da área de estudos (ROSA 1985). 
Em gabinete se elaboraram diferentes documentos cartográficos, como o mapa de elementos geomorfológicos (mapeamento dos divisores d'água, rupturas de declives, talvegues fluviais, etc.), mapa clinográfico, mapa hipsométrico e o mapa dos padrões de formas semelhantes do relevo da área de influência do Escudo Sul-Rio-Grandense no município de Pelotas. Ademais, mapearam-se os diferentes tipos de usos e coberturas da terra na área de estudos. O mapeamento foi realizado a partir de técnicas de Sensoriamento Remoto. Utilizou-se de processamento digital de imagem de satélite de resolução espacial de 30m, bandas 1,2,3,4 e 5, do satélite Landsat (5) sensor TM, datada de 28 de outubro de 2011 e disponibilizada pelo Instituto Nacional de Pesquisas Espaciais (INPE). A imagem foi georreferenciada a partir da base cartográfica de Hasenack \& Weber (2010). Para o mapeamento dos usos e coberturas da terra sobre a área de estudos, foram realizadas aplicações de contrastes, elaborações de composições coloridas (123 e 453) e classificações digitais supervisionadas pelo método de máxima verossimilhança.

As atividades de campo consistiram de verificações dos dados levantados e produzidos em gabinete, enquanto verdades terrestres, de análises visuais e táteis de materiais pedogenéticos e na identificação, localização, registros fotográficos e análise dos diferentes tipos de morfodinâmicas nos padrões de formas semelhantes do relevo mapeados. Os campos ocorreram em dias consecutivos de ocorrências pluviométricas.

\section{Resultados e discussões}

\subsection{Padrões de formas semelhantes de relevo na área de estudos}

$\mathrm{Na}$ área do Escudo Sul Rio-Grandense no município de Pelotas foram identificados e mapeados padrões de formas semelhantes de relevo em morros, morrotes, colinas e planícies (planícies fluviais e alveolares) e cabeceiras de drenagens (Figura 02).

$\mathrm{Na}$ área de estudos se destacam os relevos em morros; estes cobrem uma superfície de 309,23 $\mathrm{km}^{2}$ ou representam 34,42\% do modelado da área de estudos. Caracterizam-se por vertentes de $200 \mathrm{~m}$ de amplitudes altimétricas e de declividades relativamente acentuadas, comumente acima de $30 \%$. Os morrotes, embora apresentem vertentes de menores amplitudes altimétricas, também se estruturam por vertentes de relativa declividade, comumente entre $20 \%$ e $30 \%$. Cobrem $171,92 \mathrm{~km}^{2}$ ou $19,14 \%$ da área de estudos. As colinas representam os modelados transicionais entre morrotes e planícies. Apresentam vertentes de declividades relativamente baixas, mas expressivos comprimentos de rampa. Ocupam uma área de $67,87 \mathrm{~km}^{2}$ ou representam 7,55\% do modelado da área de estudos (Figura 02). 
As planícies foram seccionadas em alveolares e fluviais. As planícies alveolares representam modelados transicionais entre os morros, morrotes, colinas e as planícies fluviais. Nelas se destacam espessamentos do manto de alteração, eluviões, assim como, observam-se depósitos de aluviões. São terrenos de baixas declividades, sempre inferiores à $5 \%$, mas em cotas altimétricas bastante variadas. Ocupam $225,96 \mathrm{~km}^{2}$ ou $25,16 \%$ da área de estudos. As planícies fluviais estão situadas em cotas altimétricas inferiores à 40m e resultam superfícies de declividades de menos de 5\%. Elas ocorrem em fundos de vales de amplos interflúvios, marginais ao médio curso dos principais canais fluviais do município de Pelotas e compreendem sucessivos depósitos aluvionares. Ocupam $63,72 \mathrm{~km}^{2}$ ou 7,09\% da área de estudos (Figura $02)$.

As cabeceiras de drenagem são encontradas em todas as orientações da área de estudos. São vertentes côncavas, muitas de fundos chatos, lembram anfiteatros, que interseccionam os morros, morrotes ou colinas às planícies. Indicam localizações de nascentes fluviais. Representam $59,68 \mathrm{~km}^{2}$ ou $6,64 \%$ da área de estudos (Figura 02).

\subsubsection{Identificação de morfodinâmicas em morros, morrotes e colinas}

As morfodinâmicas do relevo, que corresponde aos atuais processos erosivos e deposicionais, estabelecem pontuais relações, com outras possíveis variáveis, com as características geológicas, dos solos, declividades, comprimentos de rampa e geometrias das vertentes, características pluviométricas e dos diferentes tipos de usos e coberturas da terra.

Sobre os morros, morrotes e colinas, observaram-se feições erosivas lineares e, sobretudo, evidências de processos erosivos laminares. A principal causa desses processos está associada a exposição do solo para práticas agrícolas, mineradoras e abertura de estradas, sem o devido cuidado técnico de implementação ou manejo.

$\mathrm{Na}$ área de estudos, conforme levantamento de usos e coberturas da terra, foram mapeados $210,16 \mathrm{~km}^{2} \mathrm{de}$ solos desnudos, ou seja, 23,4\% da área. Representam, sobretudo, áreas em preparo agrícola.

Solos expostos ficam vulneráveis aos agentes climáticos, a ação das chuvas fundamentalmente. Na área de estudos, levantamentos pluviométricos indicam a ocorrência sazonal de altos índices, médias superiores a $140 \mathrm{~mm}$ para os meses de fevereiro e julho (EMBRAPA/ UFPEL/ INMET, 2015). Também, são observáveis eventos extremos, chuvas concentradas em poucos dias que atingem valores acima das normais pluviométricas mensais (RUTZ, 2015). Sobre os solos desnudos, pelo efeito splash das gotas das chuvas (impactos hidráulicos), ocorrem quebras de seus agregados, salpicamentos, selamentos e o desenvolvimento de escoamentos superficiais, potencialmente erosivos. 


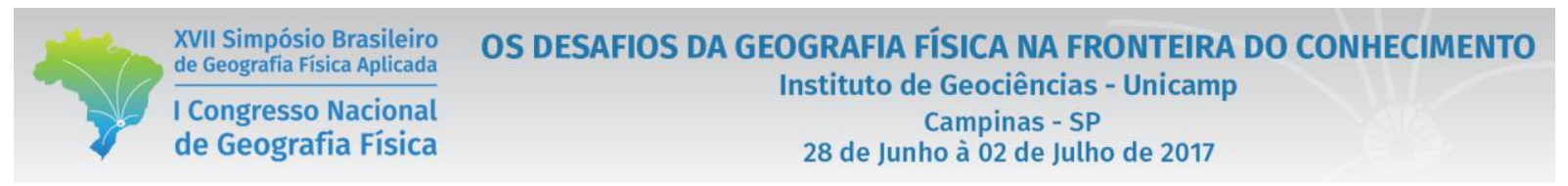

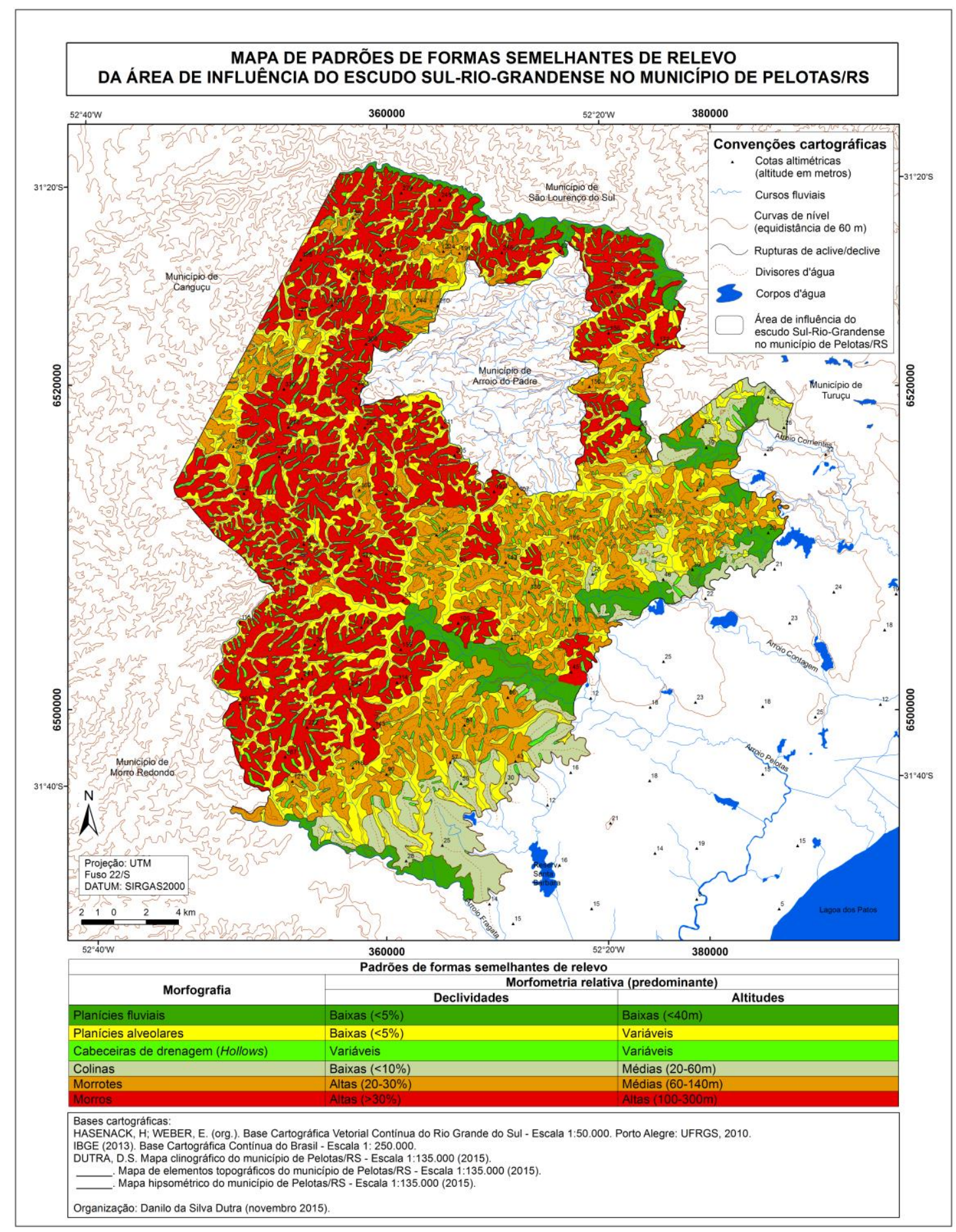

Figura 2: Mapa dos padrões de formas semelhantes do relevo da área de influência do Escudo Sul-Rio-Grandense no município de Pelotas/ RS. Fonte: Próprio autor

$\mathrm{Na}$ área de estudos, conforme levantamento de usos e coberturas da terra, foram mapeados $210,16 \mathrm{~km}^{2} \mathrm{de}$ solos desnudos, ou seja, 23,4\% da área. Representam, sobretudo, áreas em preparo agrícola. 
Solos expostos ficam vulneráveis aos agentes climáticos, a ação das chuvas fundamentalmente. Na área de estudos, levantamentos pluviométricos indicam a ocorrência sazonal de altos índices, médias superiores a $140 \mathrm{~mm}$ para os meses de fevereiro e julho (EMBRAPA/ UFPEL/ INMET, 2015). Também, são observáveis eventos extremos, chuvas concentradas em poucos dias que atingem valores acima das normais pluviométricas mensais (RUTZ, 2015). Sobre os solos desnudos, pelo efeito splash das gotas das chuvas (impactos hidráulicos), ocorrem quebras de seus agregados, salpicamentos, selamentos e o desenvolvimento de escoamentos superficiais, potencialmente erosivos.

Contiguo às áreas para lavouras, onde se observam solos desnudos, chama atenção a formação de depósitos sedimentares de granulometrias grosseiras, sobretudo em segmentos de rupturas de declive que marcam a transição entre os morros, morrotes e colinas com as planícies. Nesses casos, não há formação de feições erosivas lineares, como sulcos ou ravinas, o que pode ser um indicativo de processos erosivos laminares.

A ocorrência de seixos e matacões em segmentos de vertentes do relevo da área de estudos, onde se observam coberturas herbáceas esparsas, mediante a formação de pequenos depósitos de granulometrias bastante variadas em posições a jusante, também são indicativos da ocorrência de processos erosivos laminares.

As coberturas herbáceas, conforme levantamento de usos e coberturas da terra, ocupam uma área de $488,72 \mathrm{~km}^{2}$ e cobrem 54,4\% da área de estudos, todavia, vale o registro de que em função das variações de disponibilidade hídricas sazonais, tornam-se esparsas em períodos de estiagem.

Os seixos e matacões se destacam em altas vertentes, de declividades relativamente acentuadas, assim como, em topos convexos de morros e morrotes, sobretudo embasados pelo Granito Arroio Moinho. Sobre esses terrenos, além dos afloramentos rochosos, são verificados neossolos, mantos de alteração pouco espessos, em muitos casos, pobres em matéria orgânica, de partículas fracamente coesas e rapidamente saturados nas ocorrências pluviométricas.

As feições erosivas lineares, como sulcos e ravinas, foram observadas em campo, especialmente, nas médias e baixas vertentes de morros, morrotes e colinas, sobre neossolos e argissolos, e resultam do escoamento superficial concentrado, orientado pelas declividades e geometrias, especialmente convexocôncavas, a partir de terrenos de solos desnudos, em preparos agrícolas não terraceados, e ou de coberturas herbáceas esparsas.

Também foram observadas feições erosivas lineares, como sulcos, ravinas e voçorocas, a partir da atuação do escoamento subsuperficial nos processos erosivos, em estradas não pavimentadas. Os sulcos e ravinas ocorrem sobre as estradas, quando estas acompanham o declive das vertentes; as voçorocas ocorrem marginais as vias, paralelas a taludes de cortes que funcionam como barreiras à dissipação do escoamento, 
XVII Simpósio Brasileiro

de Geografia Física Aplicada

I Congresso Nacional

de Geografia Física
OS DESAFIOS DA GEOGRAFIA FÍSICA NA FRONTEIRA DO CONHECIMENTO

Instituto de Geociências - Unicamp

Campinas - SP

28 de Junho à 02 de Julho de 2017

canalizando-o, formando incisões de maiores profundidades, até atingir o escoamento subsuperficial (Figura 3 A e B).

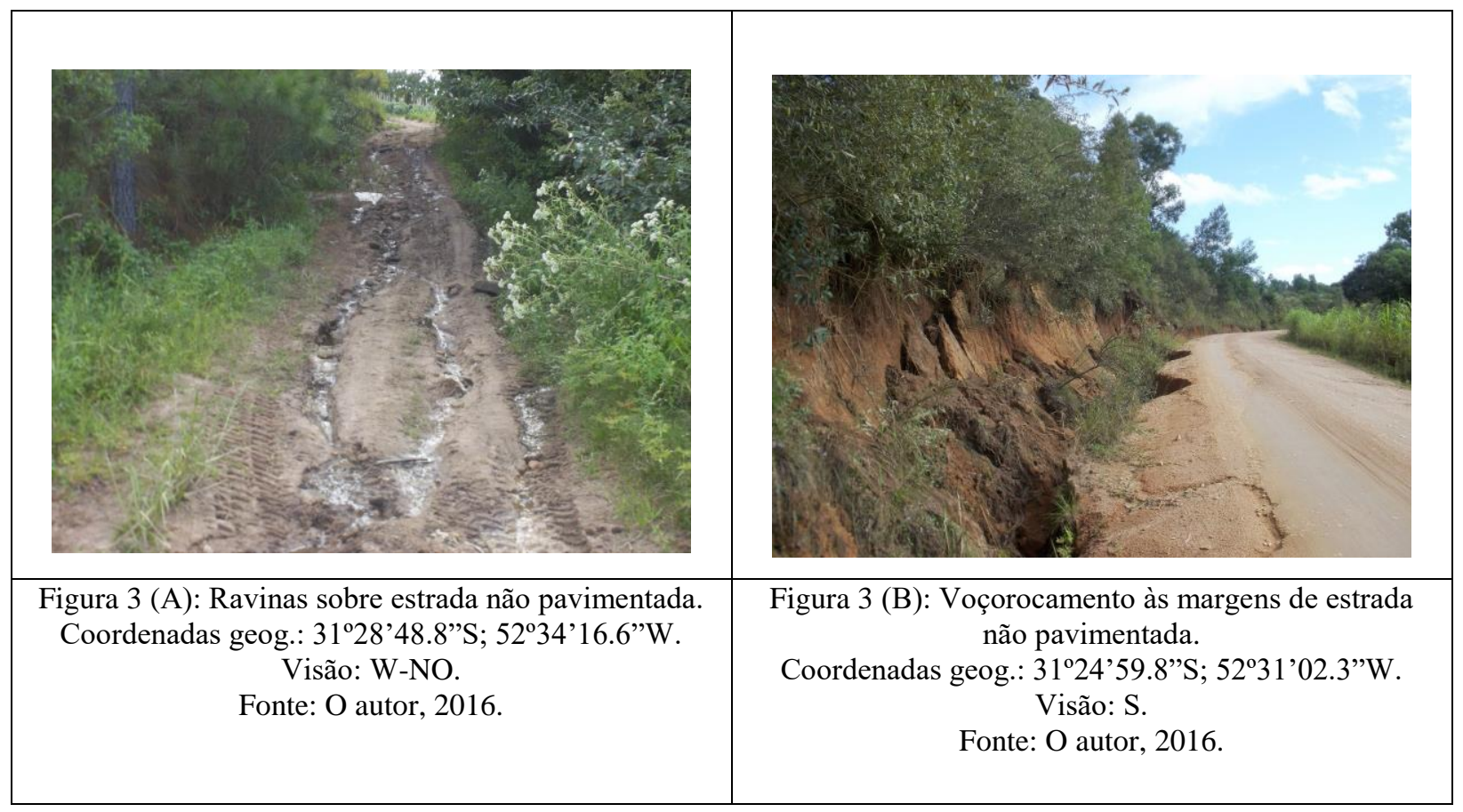

\subsubsection{Identificação de morfodinâmicas em planícies e cabeceiras de drenagens}

Sobre as áreas de planícies, alveolares e fluviais, identificaram-se formações de áreas úmidas, com dimensões que variam de 20 e 100 metros de largura, regionalmente conhecidas como banhados. Essas áreas ficam mais evidentes quando da ocorrência de maiores índices pluviométricos e ascensão do lençol freático. Essas áreas possuem importância ecológica, pela biodiversidade que comportam, e hidrológica, pois funcionam como reguladoras da vazão fluvial. Em momentos de maiores índices pluviométricos as áreas úmidas retém a água das chuvas e nos períodos de estiagem contribuem para manter a perenidade dos cursos fluviais adjacentes.

Todavia, dadas suas características geomorfológicas e pedológicas, superfícies planas e de baixas declividades, ocorrência de um manto de alteração mais desenvolvido, formação de planossolos, tornamse, posterior aterramentos, atrativas às práticas agrícolas.

As cabeceiras de drenagens, por suas geometrias côncavas, são áreas concentradoras de fluxos hídricos, superficiais e subsuperficiais, onde se observam mantos de alteração mais espessos e nascentes fluviais. $\mathrm{Na}$ área de estudos foram mapeadas 1587 cabeceiras de drenagens. Esses segmentos de vertentes estabelecem uma conexão muito dinâmica de escoamentos entre os morros, morrotes e colinas com as 
planícies, sobretudo alveolares. Ao abrigarem nascentes fluviais, esses segmentos de vertente são legalmente reconhecidos como áreas de preservação permanente, todavia, conforme mapeamento de usos e coberturas da terra e observações de campo, identificam-se alguns usos em conflitos.

Nas áreas de planícies, em segmentos marginais aos canais fluviais, do alto ao médio curso, chamam atenção as formações de depósitos sedimentares de granulometrias grosseiras e os solapamentos de taludes fluviais (Figura 4 A e B).

Os solapamentos de taludes fluviais, em muitos casos, estão associados à retirada da vegetação ciliar. $\mathrm{O}$ sistema radicular da vegetação desempenha importante papel na contenção das quedas dos taludes. Tais solapamentos são comumente observados nos altos cursos fluviais, em áreas próximas às cabeceiras de drenagens e aos divisores d'água, setores que respondem rapidamente as ocorrências pluviométricas, com alterações abruptas de suas vazões.

As formações de depósitos sedimentares, de granulometrias mal selecionadas, são indicativos das periódicas inundações das planícies. A mobilização e deposição dos sedimentos ocorre, sobretudo, durante eventos climáticos extremos. Rutz (2015) identificou no município de Pelotas, do começo do século XX ao início do século XXI, a ocorrência de, ao menos, dezenove eventos climáticos extremos, resultando enxurradas, qualificadas como "inundações bruscas" (CASTRO, 2003, p. 50 citado por RUTZ, 2015, p. 36); vide o evento ocorrido entre os dias 28 e 29 de janeiro de 2009, que marcou $600 \mathrm{~mm}$ de chuvas, muito acima da média para o mês, de 107 mm (Jornal Tradição Regional, 2009, apud Rutz, 2015).

Barras fluviais também são observáveis no leito dos cursos fluviais; mais evidentes em segmentos do médio curso, considerando-se os perfis longitudinais fluviais destes. Há a impressão de redução da profundidade dos leitos fluviais, do seu assoreamento, e da ampliação das distâncias do perfil transversal de suas calhas, mediante o afastamento entre suas margens pela progressiva queda de taludes.

\section{Considerações finais}

Este trabalho possibilitou a identificação e o mapeamento de padrões de formas semelhantes de relevo na área de influência do Escudo Sul-Rio-Grandense no município de Pelotas, RS, assim como, de suas principais morfodinâmicas. O êxito na investigação realizada se deve a consultas a trabalhos antecessores, proponentes metodológicos e a trabalhos outros que também têm a área de estudos como objeto de pesquisa. 


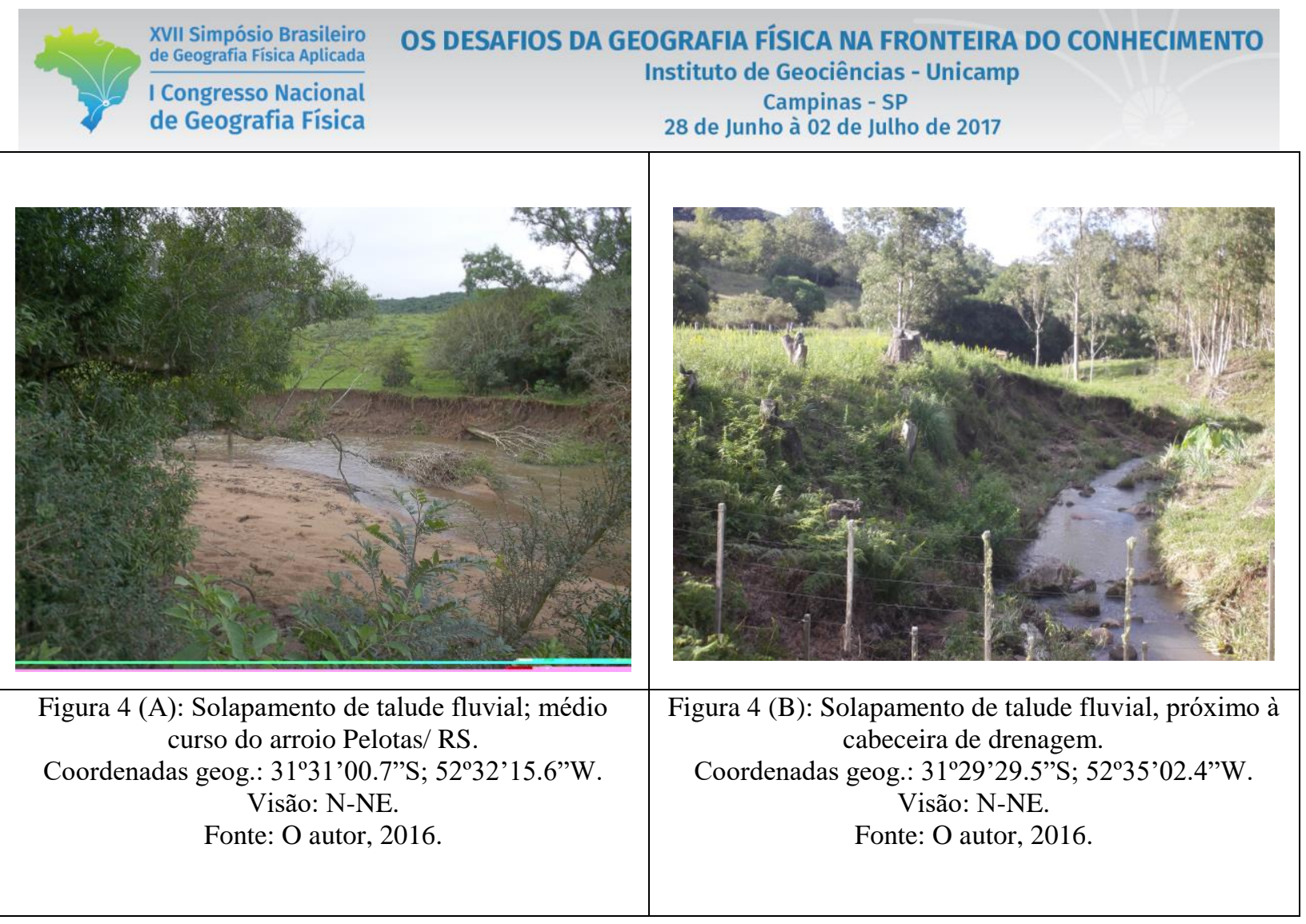

Os dados apresentados corroboram para o projeto de mapeamento geomorfológico do município de Pelotas/ RS, fornecendo informações morfológicas e morfodinâmicas do relevo. Os processos erosivos, os assoreamentos fluviais e as inundações compreendem morfodinâmicas do relevo que resultam severos impactos ambientais na área de estudos.

Os processos erosivos, assoreamentos fluviais e as recorrentes inundações, considerando-se suas implicações, prejuízos ecológicos e sociais, requerem estudos detalhados. Os diagnósticos aqui concebidos, acerca do mapeamento de padrões de formas e morfodinâmicas de relevo associadas, trazem alguns subsídios para melhor entendimento desses processos e da localização de suas ocorrências. Diagnósticos são premissas básicas para o desenvolvimento de planos de ações mitigadoras de impactos ambientais ou de recuperação de áreas degradadas.

\section{Referências bibliográficas}

AB' SABER, A. N. Um Conceito de Geomorfologia a Serviço das Pesquisas sobre o Quaternário. Geomorfologia 18. São Paulo: IGEOG-USP, 1969.

ARGENTO, M. S. F. Mapeamento Geomorfológico. In: GUERRA, A. J. T. \& CUNHA, S. B. Geomorfologia: Uma Atualização de Bases e Conceitos. Rio de Janeiro: Bertrand Brasil, 1995. p. 365-392.

CUNHA, N. G.; SILVEIRA, R. J. C. Estudos dos solos do município de Pelotas. Pelotas: EMBRAPA/ CPACT, Ed. UFPel, 1996. 50p. 
CPRM. Mapa Geológico do Estado do Rio Grande do Sul, escala 1:750.000. WILDNER, W. et al. Porto Alegre: CPRM, 2010.

DUTRA, D.S. O Mapeamento Geomorfológico da área de influência do Escudo Cristalino no município de Pelotas/RS. In: ANAIS DO XI SIMPÓSIO NACIONAL DE GEOMORFOLOGIA - SINAGEO. Universidade Estadual de Maringá: UEM. Maringá/PR, ago. de 2016.

EMBRAPA/UFPEL/INMET. Disponível em: http://wp.ufpel.edu.br/agrometeorologia/informacoes/clima-depelotas/. Acesso em: 30/07/2015.

FLORENZANO, T. G. Introdução à Geomorfologia. In.: FLORENZANO, T. G. (Org.). Geomorfologia: conceitos e tecnologias atuais. São Paulo: Oficina de Textos, 2008. p. 12-34

GUERRA. A. J. T. Processos erosivos nas encostas. In: GUERRA, A.J.T; CUNHA. S. B (Orgs). Geomorfologia: uma atualização de bases e conceitos. Rio de Janeiro: Bertrand Brasil, 2009.

HASENACK, H.; WEBER, E. (ORGS.) Base cartográfica vetorial contínua do Rio Grande do Sul - escala 1:50.000. Porto Alegre: UFRGS - IB - Centro de Ecologia. 2010. 1 DVD-ROM (Série Geoprocessamento, 3).

INPE, Instituto Nacional de Pesquisas Espaciais. Imagens do satélite Landsat TM5 (222/82)

IBGE, Instituto Brasileiro de Geografia e Estatística. Censo Demográfico do Rio Grande do Sul. Disponível em http://www.cidades.ibge.gov.br/xtras/perfil.php?lang=\&codmun=431440\&search=rio-grande-do-sul|pelotas

Consulta em: 28/04/2010.

PREFEITURA MUNICIPAL DE PELOTAS/ RS. Dados gerais do município de Pelotas/ RS. Disponível em <http://www.pelotas.rs.gov.br/cidade/dados-gerais.php> Consulta em: 04/02/2013.

RODRIGUES, C. Geomorfologia aplicada: Avaliação de experiências e de instrumentos de planejamento físico-territorial e ambiental brasileiros. Tese de Doutorado em Geografia Física. Departamento de Geografia da Faculdade de Filosofia, Letras e Ciências Humanas da Universidade de São Paulo, 1997, 280 p.

ROSA, M. Geografia de Pelotas. Pelotas: Editora da Universidade Federal de Pelotas, 1985.

ROSS, J. L. S. O Registro Cartográfico dos Fatos Geomorfológicos e a Questão da Taxonomia do Relevo. Revista do departamento de Geografia, n. 6, FFLCH/USP, São Paulo, 1992. P. 17-29.

RUTZ, E. C. Análise histórica das enxurradas no município de Pelotas e as conseqüências da enxurrada de 2009 na Bacia Hidrográfica do Arroio Quilombo, Pelotas/RS. Dissertação (Mestrado) - Programa de PósGraduação em Geografia, Instituto de Ciências Humanas, Universidade Federal de Pelotas, 2015. 124 f. 